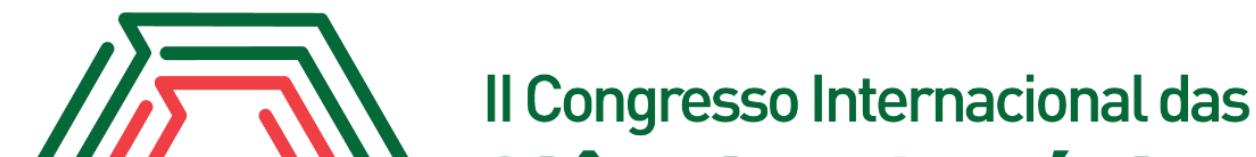 Ciências Agrárias COINTER - PDVAgro 2017
}

\section{EDUCAÇÃO DE CAMPO NA ESCOLA ESTADUAL PADRE MIGUELINHO NO MUNICÍPIO DO NATAL/RN}

\author{
Apresentação: Pôster
}

Houtran Lima da Silva ${ }^{1}$; Angélica Érica da Silva Sotero²; Hallyson Diego Mendes Braz ${ }^{3}$; Francidalva Vieira Alves ${ }^{4}$; Rosangela Dala Possa ${ }^{5}$

\section{Introdução}

A agricultura orgânica vem ganhando espaço no cenário urbano mundial a partir da preocupação da sociedade e organizações em garantir uma alimentação saudável e de caráter sustentável para as presentes e futuras gerações. Devido a essa tomada de consciência, é notória a participação ativa de comunidades familiares que cultivam a agricultura orgânica nas grandes capitais a fim de abastecer os grandes centros de mercado, feiras e pontos de vendas. Em meio a essa alternativa ambiental de sistema de produção, práticas e técnicas agroecológicas estão assumindo o progresso do plantio de diversas culturas sustentáveis e uma delas é a Compostagem.

Conforme Kiehl (1985) cita que a compostagem é um processo biológico de transformação da matéria orgânica crua em substâncias húmicas, estabilizadas, com propriedades e características completamente diferentes do material que lhe deu origem. Isso quer dizer que, os seus fatores de microorganismo, umidade, aeração, temperatura e a relação carbono/ nitrogênio, são os principais fatores que governam a compostagem.

Isso mostra que é fundamental conciliar a agricultura convencional e percorrer em direção de uma agricultura autossustentável e menos impactante ao meio ambiente. A agricultura orgânica mostra-se como uma área em desenvolvimento que podem trazer amplos benefícios para quem produz, quem consome e para o conjunto da natureza.

\footnotetext{
${ }^{1}$ Pós-graduando em Gestão Ambiental, Instituto Federal do Rio Grande do Norte, houtran.silva@gmail.com

2 Pós-Graduanda em Gestão Ambiental, Instituto Federal do Rio Grande do Norte, angelicas.sotero@gmail.com

${ }^{3}$ Pós-graduando em Gestão Ambiental, Instituto Federal do Rio Grande do Norte, hallysonbraz@gmail.com

${ }^{4}$ Pós-Graduação em Gestão Ambiental, Instituto Federal do Rio Grande do Norte, francydalva18@hotmail.com

${ }^{5}$ Doutoranda em Engenharia Química, Universidade Federal do Rio Grande do Norte, rosangeladpossa@gmail.com
} 
O Projeto propõe o desenvolvimento de uma horta orgânica provenientes dos resíduos gerados na escola, que vise interagir o aluno com o meio ambiente, explorando a variedade de aprender e a cultivar hortaliças de origem orgânica, proporcionando uma área verde, onde todos se sintam capazes de aprender e ao mesmo tempo de promover a saúde e a interação com o meio ambiente.

Com isto, o projeto em questão tem como objetivo de incentivar os alunos da Escola Estadual Padre Miguelinho do município de Natal/RN a fazer o seu próprio composto natural e assim, produzir sua própria horta orgânica, cultivando seus alimentos com valores nutricionais na merenda escolar, garantindo a destinação correta do material orgânico depositado e/ou lançado incorretamente.

\section{Fundamentação Teórica}

O meio ambiente abrange tudo que existe no planeta, os seres vivos e coisas não-vivas. É de extrema importância a sua preservação para que se possa conviver em um lugar harmonioso e que proporcione melhor qualidade de vida para os seus habitantes. Para que ocorra a conservação e reduza impactos negativos ambientais são necessárias medidas mitigadoras como a sustentabilidade.

De acordo com Boff (2012, p.107):

Sustentabilidade é toda ação destinada a manter as condições energéticas, informacionais, físico-químicas que sustentam todos os seres, especialmente a Terra viva, a comunidade de vida e a vida humana, visando a sua continuidade e ainda a atender as necessidades da geração presente e das futuras de tal forma que o capital natural seja mantido e enriquecido em sua capacidade de regeneração, reprodução e co-evolução.

Este aspecto é mencionado por Nalini (2003) que proteger a natureza precisa ser tarefa permanente de qualquer ser pensante e aprender a conhecê-la e respeitá-la pode levar uma vida inteira. $\mathrm{O}$ ambiente escolar desperta nos alunos mudanças e ter na prática um laboratório vivo proporciona um desenvolvimento de práticas pedagógicas em conjunto com as Ciências Agrárias e a Educação Ambiental, estreitando a teoria com a prática de forma interdisciplinar e multidisciplinar, entre alunos e agentes sociais envolvidos.

Pimenta (2011 p.5) sustenta que é fundamental que se lance mão da educação ambiental na promoção de uma nova cultura alimentar nas escolas, fazendo-os conhecer a importância dos alimentos, higienização, valor nutritivo e produtos alimentícios pouco nutritivos, levando-os a 
consumir aqueles mais naturais e nutritivos. A Organização Mundial da Saúde (2000) define que uma das melhores formas de promover a saúde é através da escola. Pode se perceber que a escola é um espaço social, onde muitas pessoas convivem, aprendem e trabalham, onde os estudantes e os professores passam a maior parte de seu tempo e esta interação de convívio é fundamental para a realização do projeto da horta orgânica.

\section{Metodologia}

As atividades foram realizadas em uma Escola de Educação do ensino Fundamental e Médio chamado Escola Estadual Padre Miguelinho. A mesma encontra-se localizada na zona leste no bairro do alecrim no município de Natal/RN, localizando-se a uma latitude $5^{\circ} 47^{\prime} 36.16^{\prime \prime S}$ e a uma longitude $35^{\circ} 12^{\prime} 52.32^{\prime \prime} \mathrm{O}$.

No período da pesquisa a escola atendia cerca de 337 alunos de manhã e 702 alunos no turno vespertino, contemplando as séries do $5^{\circ}$ ano do ensino fundamental ao $3^{\circ}$ ano do ensino médio, distribuídas nos dois turnos: matutino e vespertino, no entanto, o recorte da pesquisa contemplou apenas os alunos do $1^{\circ}$ ano do ensino médio regular na disciplina de ciência. O período da pesquisa ocorreu no mês de maio a agosto de 2017, com a supervisão de professores de ciências e a direção da escola.

Este estudo na metodologia de Ludke e André (1986) apontam métodos de coleta de dados utilizados na pesquisa qualitativa, tais como: observação, entrevista e pesquisa ou análise documental. O tipo de pesquisa realizada foi à exploratória definida no estudo do caso e levantamento de dados com relação direta à relatos de experiências da própria escola. As etapas do ciclo da pesquisa como mostra a sequência de imagem (figura 01) constituem em uma aula teórica para abordar temas do ciclo da matéria orgânica, manejo, funcionamento e demais processos associados à produção de compostagem sem adição de produtos químicos.

Figura 01 - Etapas do ciclo da pesquisa. Fonte: Elaborado pelos autores (2017).
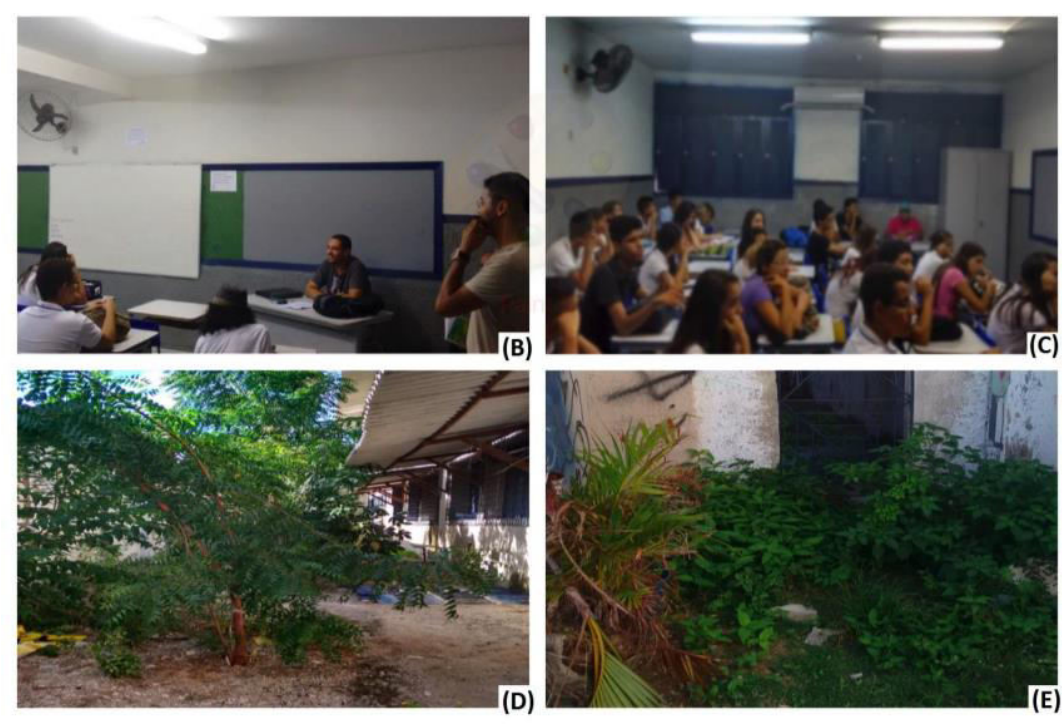


\section{Resultados e Discussões}

A intervenção na escola foi de uma válida experiência, pois pode-se observar o quanto é importante que as práticas coletivas sejam incentivadas, além de contribuir para uma boa alimentação saudável e a prática do convívio no ambiente escolar.

O projeto que tentou-se desenvolver, poderá servir como modelo futuro para outras escolas que não sabem destinar os resíduos gerados da própria cozinha, bem como, possibilitar a trabalhar assuntos relacionados às Ciências Agrárias e agroecológica de forma interdisciplinar.

No entanto, é fundamental o envolvimento de toda a escola para que as experiências adquiridas e a interdisciplinaridade sejam de fato consolidadas no sentido de reconhecer e valorizar o desenvolvimento de projetos pedagógicos alunos v.s. escola para que possam contribuir de forma eficaz as boas práticas de iniciativas relacionadas ao meio ambiente.

Percebemos na sala de aula que os alunos não sabem da existência dos problemas gerados pelos resíduos, sua produção, disposição e nem tão pouco da geração do composto orgânico gerado pelas sobras de alimentos desperdiçados. Diante do exposto, há vários fatores que podem ser inseridos na escola, como: a prática no desenvolvimento agroecológico de uma horta. A didática relacionado a ciências agrárias é uma atividade que exige além de esforços contínuos, pesquisas relacionadas sobre o tema que se deseja trabalhar juntamente com os alunos.

Infelizmente, em primeiro momento, não foi dado continuidade ao projeto no interior da escola devido a fatores de diversas naturezas, principalmente financeira, devido o quadro mundial atual se deparar com uma crise que vem afetando os principais instrumentos de gestão de uma sociedade que são: segurança, saúde e educação.

Entretanto, foi observado que a escola não manifestou o interesse da implantação do projeto, e com isto, acarretou na paralisação e/ou suspensão dos trabalhos que beneficiaria não somente aos alunos, mas também a toda comunidade escolar.

\section{Conclusões}

O projeto que tentou desenvolver alcançou bons resultados positivos a partir do momento em que foi possível transmitir o conhecimento aos alunos sobre os conceitos e valores de resíduos sólidos, meio ambiente, reciclagem e compostagem, bem como, a capacitação dos professores para lidar com o processo de compostagem, proporcionando colocá-los em prática seus conhecimentos socioambientais e fortalecendo a prática da Ciência Agrária e Educação Ambiental no ensino, para 
com isso, contribuir no processo de formação de cidadãos, despertando seu interesse no meio ambiente.

Sem recurso financeiro por parte da escola (seja para pagar a horas extras de professores, ou algo que é necessário para a compra de material), acarretou-se a não continuidade, paralisação e/ou suspensão do projeto que beneficiaria não somente aos alunos, mas também a toda comunidade escolar.

Embora não tenha sido em um momento bem oportuno para prática na escola, este projeto servirá de alicerce para que futuramente a ideia possa vir a ser praticada não só no objeto de intervenção, como também, em outro ambiente escolar que envolva a prática das Ciências Agrárias.

\section{Referências}

BOFF, L. Sustentabilidade: tentativa de definição. Disponível em: <https://leonardoboff.wordpress.com/2012/01/15/sustentabilidade-tentativa-de-definicao/>. Acesso em 23 mai. 2017.

KIEHL, E. J. Fertilizantes Orgânicos. São Paulo: Editora Agronômica Ceres Ltda., 1985, p. 492.

LUDKE, M. e ANDRÉ, M. E. D. A. Pesquisa em educação: abordagens qualitativas. São Paulo: EPU, 1986.

NALINI, R. Justiça: Aliada Eficaz da Natureza. In: TRIGUEIRO, A. (coord.) Meio Ambiente no Século 21: 21 especialistas falam da questão ambiental nas suas áreas de conhecimento. Rio de Janeiro: Sextante, 2003.

ORGANIZAÇÃO MUNDIAL DA SAÚDE - OMS. Local Action: creating health promoting schools, 2000.2 Disponível em: <http://www.who.int/school_youth_health/resources/information_series/en/index.html> Acesso em 20 maio 2017. (Tradução nossa).

PIMENTA, J. C.; RODRIGUES, Keila da Silva Maciel. Projeto Horta Escola: Ações de Educação Ambiental na Escola Centro Promocional Todos os Santos de Goiânia/GO. Simpósio de Educação Ambiental e Transdisciplinaridade UFG / IESA / NUPEAT - Goiânia, maio de 2011. 